\title{
Simulation of Shipping Size Effects for Transportation and Order Quantity in a Supply Chain
}

\author{
EunSu Lee ${ }^{1}$ and Kambiz Farahmand ${ }^{2}$ \\ 1. Upper Great Plains Transportation Institute, North Dakota State University, Fargo ND 58102, USA \\ 2. Department of Industrial and Manufacturing Engineering, North Dakota State University, Fargo ND 58105, USA
}

\begin{abstract}
This paper investigated the interaction effects between inventory and transportation strategies in the logistics network. Demand volumes and shipping sizes were simulated as part of a new conceptual model using a discrete event simulation by minimizing the total logistics cost in the supply chain. The experiments indicate that the full truckload scenario leads to cost efficiency and the larger demand size results in smaller cost per unit based on economies of scale. Considering the interaction effects, demand size has a greater impact on cost reduction than shipping size. The total logistics cost in the system is dependent on replenishment rate and flow rates from the higher to the lower echelon. High inventory cost is the result of a fast replenishment rate and frequent orders, while shipping cost is dependent on the flow rates in a process and total travelling time or total travelling distance. Shipping size also has an impact on the level of service and the total cost along with effective order variability.
\end{abstract}

Key words: Base stock inventory, truck load, logistics and transportation.

\section{Nomenclature}

$F Q_{f} \quad$ Number of factories

$F Q_{r} \quad$ Number of RDCs

$F Q_{w} \quad$ Number of warehouses

$F F_{f t} \quad$ Fixed facility cost of a factory during the period $t$

$F F_{r t} \quad$ Fixed facility cost of a RDC during the period $t$

$F F_{w t} \quad$ Fixed facility cost of a warehouse during the period $t$

$F V_{f t} \quad$ Variable facility cost of a factory during the period $t$

$F V_{r t} \quad$ Variable facility cost of a RDC during the period $t$

$F V_{w t} \quad$ Variable facility cost of a warehouse during the period $t$

$Q_{\text {frpt }} \quad$ The flow of product $p$ shipped from factory to RDC during the period $t$

$Q_{r w p t} \quad$ the flow of product $p$ shipped from RDC to warehouse during the period $t$

$\operatorname{Tr} V_{z} \quad$ Variable transportation cost per hour

$\operatorname{TrF}_{t}{ }^{z} \quad$ Fixed transportation cost of a type of truck $Z$ during the period $t$

Corresponding author: EunSu Lee, Ph.D., research fields: freight modeling, logistics, supply chain, and spatial modeling in transportation and logistics. E-mail: eunsu.lee@ndsu.edu.
$T Q_{z}$
Number of trucks of the size of $z$
$D_{w p} \quad$ Demand quantity of product $p$ for a
$D_{r p} \quad$ Demand quantity of product $p$ for a RDC in the unit of pallet (lot size)
$R O P_{w p} \quad$ Reorder point of product $p$ at a warehouse
$R O P_{r p} \quad$ Reorder point of product $p$ at a RDC
$I_{w p}$
$I_{r p}$
$A I_{r p t}$
Current inventory of product $p$ at a warehouse
$A I_{r p t} \quad$ Average inventory level of product $p$ at a RDC during the period $t$
$A I w_{p t} \quad$ Average inventory level of product $p$ at a warehouse during the period $t$
$L_{p} \quad$ Loading quantity of product $p$ on a pallet
$\mathrm{Pr}_{p} \quad$ Market price of product $p$

\section{Introduction}

Companies experience business expansion or contraction as a result of market changes. Efficient coordination of logistics networks is required in today's competitive market. Consequently, some companies may consider redesigning their logistics network model, including manufacturers, distribution centers, and warehouses, to minimize total cost and 
maximize customer service. Long-term planning for the network design is a consideration when investing in resources or contracts with third-party logistics companies.

Total cost is determined based on location, transportation, and inventory costs. To optimize the logistics network model, the factors affecting cost are considered. Pujawan [1] studied the effective lot sizing rules by comparing the variance of order interval and quantity. He focused on the order variability under different order lot sizes without considering shipping cost and location capacity in a single level system from suppliers to end customers. Tancrez et al. [2] introduced a three-level supply chain model which considered shipment size. The three-level supply network model has fixed locations and fixed constant production and demand rate. Various shipment sizes are reflected from the different levels. The majority of previous studies in the literature use mathematical optimization techniques or Monte Carlo simulation as well as a heuristic approach. Tsao et al. [3] considered store density in a cluster of distribution centers to partition distribution center districts. To consider complex and large network systems in a company, the discrete simulation technique is used to deal with the complexity of factors and strategies [4]. As in earlier research, because of the many assumptions and numerous responses to potential factors of logistics network simulation, the abstracted process, in lieu of the detailed process, is considered [5, 6] as along with a metamodel [7]. Kleijnen [8] indicated that the use of simulation as a tool raises methodological concerns: verification, sensitivity or "what-if" analysis, optimization, and robustness and uncertainty analysis for strategic levels.

Anily et al. [9] researched fixed truck rental cost and a constant replenishment interval inventory policy. They used deterministic demand and assumed the demand is uniform for all regions through two echelons. $\mathrm{Qu}$ et al. [10] modeled a logistics network with stopover, travel, and shipping cost. Jayaraman [11] studied a logistics network with the space of locations limited by the dimension of products. Apart from the physical dimensions, the coordination of order quantity and reorder point plays an important role in a supply chain system [12]. In light of these factors, uncertainties are absorbed upstream by keeping safety stock. When the information of order quantity and reorder point is shared, managerial practice can reduce the bullwhip effect in the supply chain [13].

In the supply chain system, most of the products flow on pallets or in bulk from higher echelons. A pallet is the typical unit in a supply chain for inbound and outbound processes. Vroblefski et al. [14] researched lot-sizing model as TL (truckload) and LTL (less-than-truckload) under a differential transportation cost structure. Chu [15] studied mode selection between TL and LTL carriers for cost savings for a given company. Different products have different dimensions and lot-sizes. However, the study did not consider inventory rules. To develop efficient transportation and logistics systems for a company, a discrete simulation technique is generally adopted to overcome complexity and a variety of factors and strategies [4, 7]. Because of the many assumptions and numerous responses to potential factors within a logistics network simulation, an abstracted process is considered in lieu of detailed process $[1,6]$.

In this study, a discrete-event simulation is used to experiment with the continuous base stock inventory policy integrated with shipping strategies for three different demand sizes. The simulation model collected cost data for analysis. The first objective of this study was to verify the key role of the interaction between inventory control and transportation strategy in response to the demand sizes for a multi-echelon logistics network model. This paper focuses on the interaction of demand sizes and trucking lot-sizes as a load factor for the complex logistics network design in consideration of order quantity. This study also presents the impact of sharing information about customer demand with units upstream in the supply chain. 


\section{System Description}

To manage the customer's service, there are three types of facilities in the logistics network considered in this model: factories, RDC (regional distribution centers) and warehouses as shown in Fig. 1. It is assumed that factories are not capacitated, and RDCs and warehouses have a capacity limit in this study.

Three factories manufacture different products, respectively, and serve three distribution centers. Factories operate in-house warehouses to store the manufactured products and returned products. The three RDCs have two main functions: the first is to supply products to warehouses which then serve as a main distribution center; the second is to maintain safety stocks to satisfy rush orders as they arrive. RDCs keep all products in excess of the safety stock level for unexpected sales. Forty five warehouses are assigned to one of the RDCs, and new warehouses will be allocated to the closest RDC to minimize transportation cost and shorten travel distances while considering the capacity of that RDC. All customer orders are stored in the OMS (order management system). To finalize the original orders, it will take three days to check the customer's credit. In such a system, customers are required to order products at least three days ahead of the delivery schedule. Each facility places an order to a higher echelon to maintain the customer's original demand from OMS including rush orders from the customer service center in the sales department or the customers themselves directly. To realize the benefits of the RDCs in a logistics network, the company considers both routes and the size of trucks. If RDCs do not have enough capacity for sizable carriers, the total cost can not be reduced to achieve economies of scale. The factories and the RDCs have spacious docking systems and parking lots for trucks of a gross weight of $15 \mathrm{t}$. The warehouses are located in suburban areas because of the cost of land, taxes, and building restrictions. For this reason, a gross weight of $2.5 \mathrm{t}$ to 5 $\mathrm{t}$ is the ideal truck size given their constraints. Shipping is outsourced to freight companies and factories, and the freight companies are contracted on a daily basis. Consequently, if the truck is idle, the company must still pay the shipping cost.

\section{Experiment Design}

\subsection{Objective}

The objective of this simulation study is to minimize the total cost of the overall systems in the supply chain from factories to warehouses. Total logistics cost is determined by adding the transportation cost, inventory cost, facility cost, and stock out cost (Eq. (1)).

$T C=\operatorname{Tr} C$ (transportation cost) $+I C$ (inventory cost)

$$
+F C \text { (facility cost) }+S C \text { (stock out cost) }
$$

Demand quantity and shipping size as a load factor are varied according to base stock inventory policy to

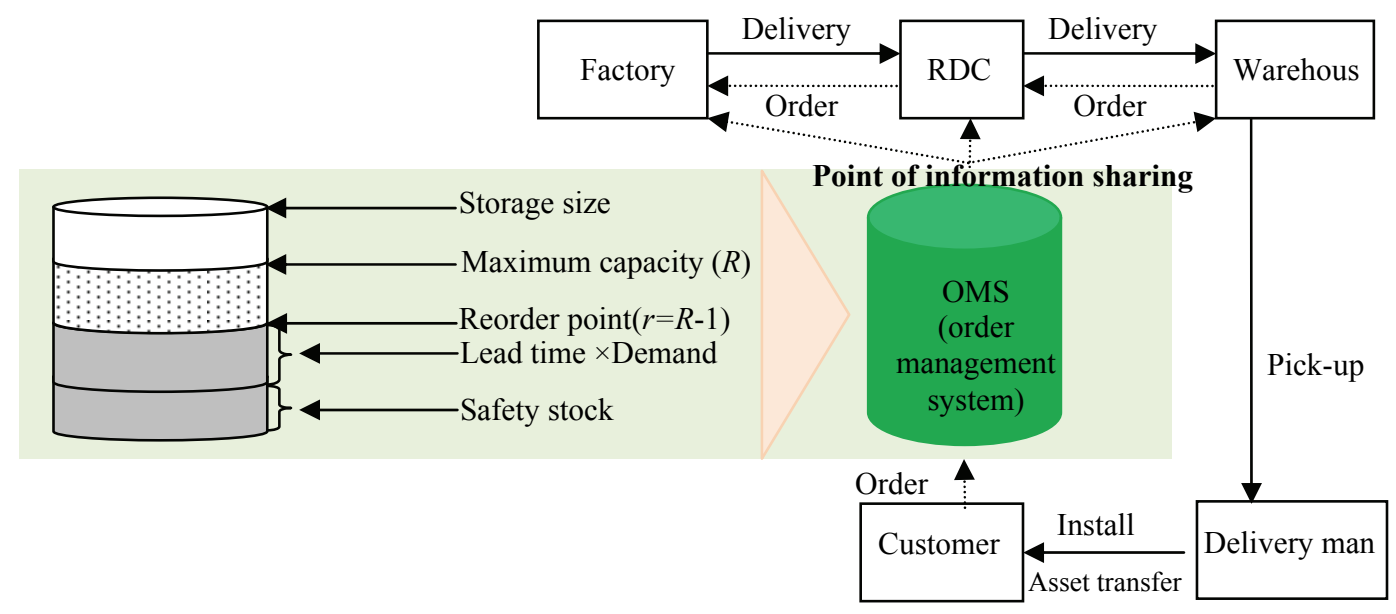

Fig. 1 Inventory and order system within three echelon supply chain model. 
achieve the research objective. Different truck configurations are considered based on different levels of echelon. $\operatorname{Tr} C$ (Eq. (2)) consists of variable transportation costs and fixed transportation costs between the manufacturers, RDCs and warehouses. Fixed transportation cost is calculated based on the different types of trucks used between the various facilities. These different truck configuration assign different fixed costs to the cost model. Variable transportation cost is determined by the hours of operation. The hours are calculated by dividing the distance by the speed of truck considering fully or partially loaded truck (load factor) and empty back-haul truck without regarding capacity or size of the trucks.

$$
\operatorname{Tr} C=\operatorname{Tr} V^{z}\left(h_{f r t}^{z}+h_{r w t}^{z}\right)+\operatorname{Tr} F_{t}^{z} \cdot T Q^{z}
$$

$I C$ consists of $O C$ (order cost) for each order and $C C$ (carrying cost) to hold the inventory during a given period. Order cost is based on one-for-one inventory policy (Eq. (3)). Order lot sizes are managed in both RDCs and warehouses. That means that the pallets could be moved from RDCs to factories or from warehouses to RDCs as part of fulfilling orders. Order cost of one-for-one policy is the frequency of orders at each facility times the cost per order. The number of units to be ordered in a RDC should be greater than the number of units (loading quantity) on a pallet for each product. In the RDCs, the total number of units is determined by subtracting the reorder point from the current inventory. The total demand is then divided by the number of products (loading quantity) on a pallet to determine the total number of pallets. In the warehouse, orders are generated when the reorder point is higher than the current inventory level. Carrying cost (Eq. (4)) is then calculated by multiplying the average number of units in the facility during a given period by $12 \%$ APR (annual percentage rate). The equations presented areas follows [16]:

$$
O C=\sum_{p=1}^{P}\left\{\operatorname{Max}\left\{0, \operatorname{Trunc}\left(\frac{D_{w p}}{L_{p}}\right)\right\}+D_{r p}\right\} \cdot C O
$$

$$
C C=\sum_{t=1}^{T} \sum_{p=1}^{P}\left\{\left(A I_{r p t} L_{p} \operatorname{Pr}_{p}\right)+\left(A I_{w p t} \operatorname{Pr}_{p}\right)\right\} \cdot(12 \%)
$$

$F C$ is the combination of $F V$ (facility variable) cost and $F F$ (fixed facility) cost. Total fixed facility cost shown in Eq. (5) is the product of the inventory level of a facility and a unit cost of a product for each facility based on the type of locations during a given period. $F V$ cost shown in Eq. (6) consists of two parts: material handling cost and other costs. Material handling cost is based on cost of operating forklifts and labor cost involved for loading and unloading.

$$
\begin{gathered}
F F=\sum_{t=1}^{T}\left(F F_{f t} \cdot F Q_{f}+F F_{r t} \cdot F Q_{r}+F F_{w t} \cdot F Q_{w}\right) \\
F V=\sum_{t=1}^{T} \sum_{p=1}^{P}\left\{F V_{f} Q_{f r p t}+F V_{r}\left(Q_{f r p t}+Q_{r w p t}\right) i\right. \\
\left.+F V_{w} 2\left(Q_{r v p t} L_{p}\right)\right\}
\end{gathered}
$$

Stock out cost is calculated based on the current inventory level and is less than the demand level during a given period (Eq. (7)). The loss is assumed at $10 \%$ of each product's market value.

$$
S C=\sum_{p=1}^{P}\left\{\operatorname{Max}\left\{0,\left(D_{w p t}-I_{w p t}\right)\right\} \cdot \operatorname{Pr}_{p}\right\} \cdot(10 \%)
$$

\subsection{Inventory}

It is assumed that inventory is based on FOB (free on board) delivery, which means that the seller or supplier takes the responsibility for transportation charges and delivery. For this reason, the supplier's inventory will be updated the moment the inbound product enters into the customer's facilities. The order is then decentralized as a pull system, which means that each facility places an order for replenishment independently as shown in Fig. 2.

\subsection{Demand and Order}

Transportation and material handling at the factory and RDC occur 24 hours a day. The orders are closed at 6 p.m. every day by the information system. The model is denoted as $r, R$ with $R=r+1$, where $R$ is maximum capacity (upper bound) and $r$ is the reorder point as 


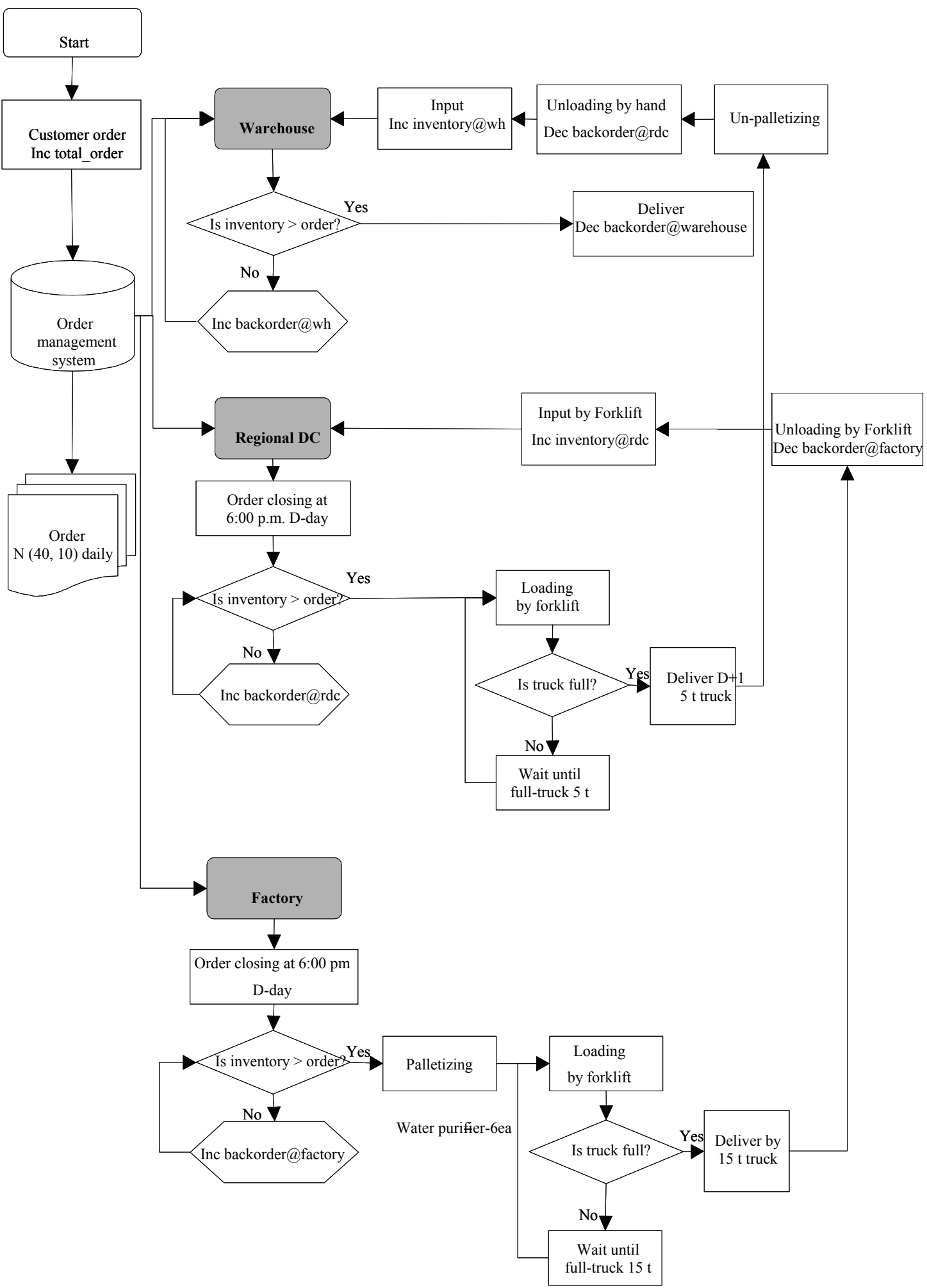

Fig. 2 Flow of order processing and delivery.

shown in Fig. 2. Only one unit is ordered when the inventory level reaches the reorder point $(r)$. For the simulation purposes, the $R$ is set as the product of maximum utilization and the storage capacity of a 
location. Each warehouse is assumed to store 500 products without consideration for the item's physical dimensions. Maximum capacity $(R)$ excludes the dock, the parking lot, dead space, office space, etc..

$\mathrm{RDC}$ has adequate parking lots, docking systems, and roads for trucks and trailers. RDC is located in suburban areas, and the warehouse is located in urban areas for quick delivery and service. The warehouse has a small parking lot and narrow access road that makes it difficult for large trailers or trucks to enter. In this study, the maximum capacity is set at the average daily demand for one day. The upper bound is calculated by max \{space $\times$ height $\times$ efficiency / pallet dimension, subjective number $\}$ at each location $i$. Melachrinoudisa et al. [17] used the warehouse-utilization ratio and the number of pallets. The maximum utilization is set equal to the capacity of a location and then is converted into the number of pallets.

In the proposed simulation model, external demand occurs at the lowest echelon, which is the warehouses. The total sales of the products, however, show annual increase. The scenarios of demand sizes are 3, 5 and 7 million products a year. The demand size is divided by the total business days (365) in a year for the daily arrival rate. Two years of outbound data are tested in the utility of STAT:FIT embedded in Promodel®. From the results, normal distribution is chosen as the distribution of choice to simulate the outbound data. The goodness of the fit test is conducted by maximum likelihood estimates with an accuracy of the FIT of 0.0003 and a level of significance of $5 \%$. From the data, each day's demand is set by $A=N(D Y / N B, D Y / N B \times$ $R D$ ), where, $A=$ daily arrival rate, $N=$ normal distribution (mean, standard deviation), $D Y=$ expected demand per year, $N B=$ business days per year, $R D=$ rate of standard deviation of the mean.

Initial inventory is set up for a new business. It is set as a default value before the entities arrive in the simulation system. Inventory cost is classified into three categories: stock out cost, holding cost and ordering cost. Stock out cost is assumed as $10 \%$ of the product margin. It is assumed holding cost consisted of storage managing cost as $7 \%$ of the average inventory, storage risk as $5 \%$ of the average inventory, and interest rate of $12 \%$ per year. Ordering cost is calculated by $\$ 1$ per item.

\subsection{Location}

Each warehouse is assigned to a RDC. A RDC distributes products to the assigned warehouses. Factory and RDC have the many-to-many $(\mathrm{m}: \mathrm{m})$ relationship, and RDC and warehouses have the one-to-many $(1: m)$ relationship to each other in terms of supply and service (Fig. 3).

The average space of factories and RDCs is 4,000 $\mathrm{m}^{2}$, and the efficiency of the locations is approximately $80 \%$ excluding dead space. Each RDC can accommodate 1,000 pallets. The average space for a warehouse is 700 square meters, and the efficiency of

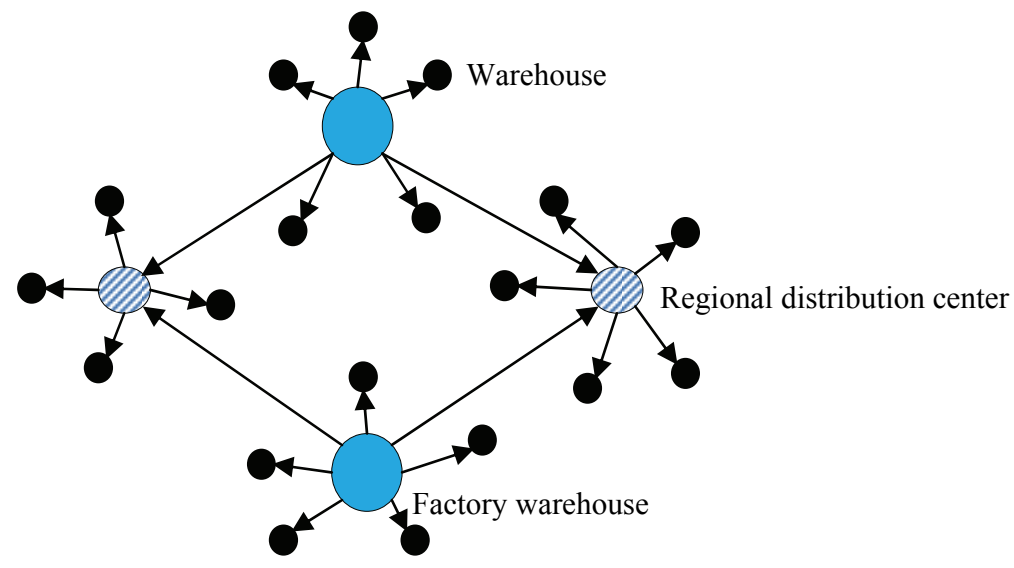

Fig. 3 Three-echelon logistics network. 
warehouses is $60 \%$. Each warehouse can store nearly 500 products regardless of the item's various dimensions. Capacities of the location exclude dock, parking lot, dead space, office space, etc.. The operation costs of locations are differentiated by the level of daily operation. The fixed cost was $\$ 7,500$ at a factory and RDC and $\$ 650$ at a warehouse. The variable cost was $\$ 3$ at a factory and $\$ 5$ at a RDC per pallet, while the variable costs were $\$ 1$ per item at a warehouse.

\subsection{Material Handling}

Forklifts are used at factories and RDCs, but not at warehouses. To use a forklift, products should be palletized at a factory and orders are placed in terms of pallet load. The number of products on a pallet varies based on different dimensions of products. For example, six items of product A along with 18 items of product $\mathrm{B}$ could be loaded on a pallet. The pallets move from a factory to a RDC and from a RDC to a warehouse. The pallets are kept in these locations until delivered. Those pallets are ungrouped at a warehouse for delivery to customers. The simulation setting for the forklift is summarized in Table 1.

\subsection{Transportation}

Each truck configuration has its own capacity to accommodate products accumulated in different units, such as weight, volume and dimension. This was tested here in two different shipment sizes of TL (truckload) shipment and LTL (less-than-truckload) shipment. TL is set at full capacity for the experiment, and LTL is at $50 \%$ of the capacity of TL.

Weight is not an issue since the company's products are dimensional products instead. In this model, the areas for palletizing and depalletizing were considered as part of the flow of products. The products were palletized with the average dimension of the SKU (stock keeping units). Palletizing time at a factory was not considered because the activity is done after production, not at the time of receiving an order. The
Table 1 Forklift operation data collected at factories and RDCs.

\begin{tabular}{lc}
\hline Activities & Quantification \\
\hline Pickup time (min) & 1 \\
Deposit time (min) & 3 \\
Travel speed in loading (m/min) & 4 \\
Travel speed not in loading (m/min) & 4 \\
Distance from shipping dock to rack (m) & 50 \\
Cost (\$) per hour & 30 \\
\hline
\end{tabular}

palletized products were moved into the loading field by a forklift. Thirty-six pallets were loaded in a 15-ton truck and 10 pallets were loaded on a 5-ton truck. The fixed cost was $\$ 130$ for a 15 -ton truck and $\$ 100$ for 5 -ton truck. The variable cost was $\$ 30$ for a 15 -ton truck and $\$ 25$ for a 5 -ton truck.

Transportation delay is a major portion of lead-time because this study considers shipping sizes in order to ship products from origin to destination. Nonetheless, speed variability is simulated to express the lead time instead of using a predetermined lead time for shipping. The empty trucks drive $U(80,18) \mathrm{km} / \mathrm{h}$, however, the loaded trucks drive $U(72,12) \mathrm{km} / \mathrm{h}$ following a uniform distribution assumption. The waiting time for deposit at each location was set by $\mathrm{U}(1,800,600) \mathrm{s}$ for inspection and documentation activities while unloading products.

LTL is loaded under $100 \%$ of the capacity of TL delivery. For example, when a factory receives the order for the quantity of $50 \%$ of $\mathrm{TL}$, the truck transports those products to the lower echelon. The lead-time might be shorter than TL. However, the cost will be increased due to the frequency. TL shipment could be designed to decrease the handling cost and variable shipping cost. It is assumed that there is no surcharge for the carriage service. The company distributes the products by the pallet unit from a supplier to a warehouse. In this model, the zone of palletizing and depalettizing were considered as steps in the flow of the products as shown in Fig. 4.

The transportation cost is calculated monthly using a fixed cost. Although, if it is over some distance of kilometers from the location specified in the contract, 
the company charges more money as an additional variable cost.

\subsection{Verification}

Verification of the conceptual logistics network model is important to determine if the simulation is working correctly. Outputs from the simulation are categorized into four groups: the number of orders and deliveries, the number of backorders, inventory levels, and costs. Animation screens were designed to see the flow of products and the movement of resources, and the changes of inventory levels and capacity. The demand and transportation policy factors are set in the "macro" menu to change simulation options easily.

The results of the simulation model will have impacts on management decisions and their outcome. Therefore, the results should be accurate and representative of the operation [18]. A variety of validation methods were introduced by Sargent $[19,20]$ including an animation, comparison to other models, degenerate tests, extreme condition tests, and historical data validation. Sensitivity analysis is conducted for validation of the model. Historical data validation to represent the reality can be used when the reality model is developed to improve the current system. Even though real data was not collected for our study, the historical method was used for validating the assumptions and general acceptance for the model scenarios. Furthermore, an operational graphics method was performed. Through this method, it was observed that the entities' dynamic behaviors continue throughout the model's runtime.

\section{Experimentation}

\subsection{Simulation}

Nine scenarios $(3 \times 3)$, including three demand sizes and three shipping sizes, were run for experimental analysis and are discussed here. Eleven months' data are collected to analyze with a one month warm-up period to reach the steady-state period in a series of replications after running all scenarios of the simulation. Farahmand et al. [21] set the warm-up period after running all the categories of the simulation scenarios. The maximum period to reach the steady-state period is set as a warm-up period in each series of replications. In the real world, the initial inventories are set up for new business, so the warm-up period does not have to be long in this simulation. Each scenario is run for 30 days to plot the warm-up period for the stable statistics and to reach steady-state outputs of entities for the simulations.

To ensure independent sample observations, bias was removed or reduced in the experiment. There are two methods for ensuring independent sample observations: running multiple replications and interval batching. In this study, the running multiple replication method is used. For the simulation experiment, the replication is considered as a sample size to avoid the bias of random variability. The replications have different seed values when ProModel ${ }^{\circledR}$ generates the random number for the simulation. The technique has an advantage in that each replication can be set with a warm-up period to avoid biased results.

\subsection{Experimental Results}

All data are mean values of day-runs from each scenario.

4.2.1 Results and Discussion

LTL is used for rush orders or for quick inventory replenishment to meet a customer's delivery date. It is also used for small quantities of items. LTL results in long distance of travel overall and it slows the overall replenishment because of the downtime and low utilization of trucks. Simulation is run with and without the stock out constraint. In this model, results show that as demand size increases, TL becomes more efficient than LTL.

Cost analysis is summarized in Fig. 5. Total cost is collected from the simulation, and unit cost is calculated to compare the transportation policies. The concern is how a company can keep the cost reasonable 


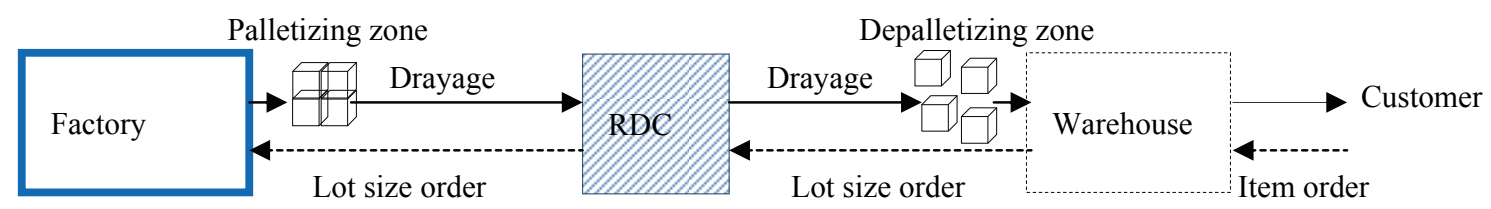

Fig. 4 Logistics scheme of the supply chain.
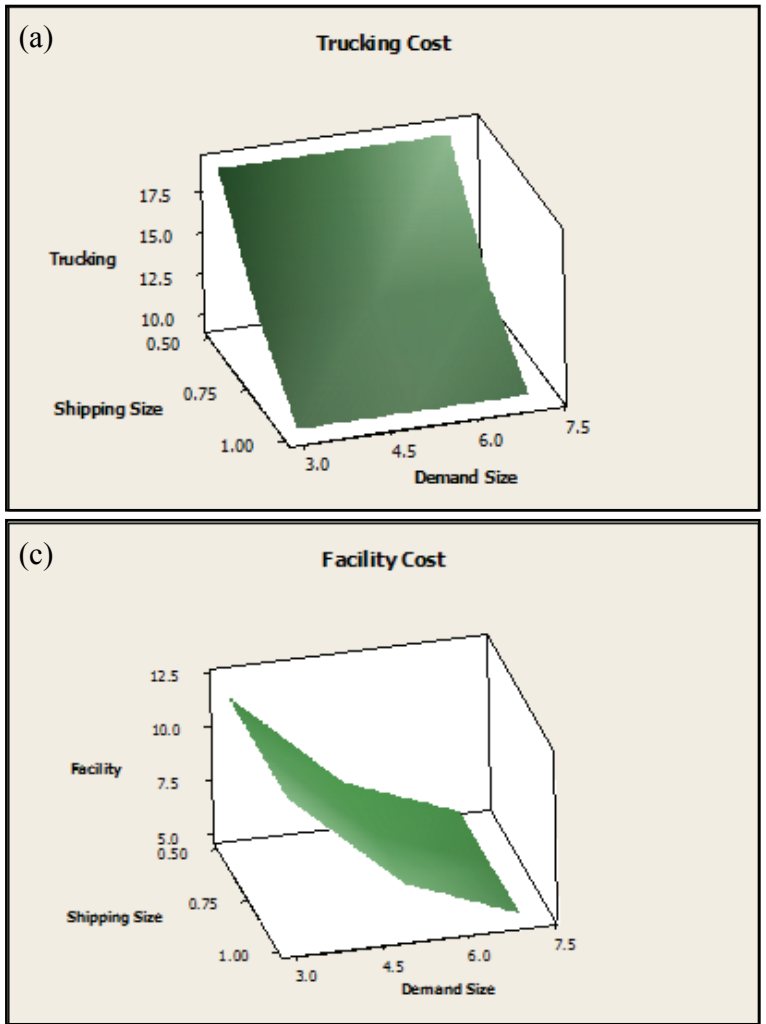

Fig. 5 Surface graphs for the cost items of each scenario.

to maximize profit. Low cost does not mean that the company would have high profit per unit with that scenario. Trucking cost decreases as the shipping size increases and as the demand size decreases. The interaction effects between the shipping size and the demand size are not significant for the trucking cost (Fig. 5a). The material handling cost decreases as the shipping size increases and as demand decreases (Fig. $5 b)$. The material handling cost is distorted when the shipping size is small and demand is up. The decrease rate of the material cost is affected much more by demand size than the shipping size (Fig. 5c). Because of economies of scale, the facility cost decreases as shipping size and demand size increase. The holding cost shows the same pattern as the facility cost (Fig.
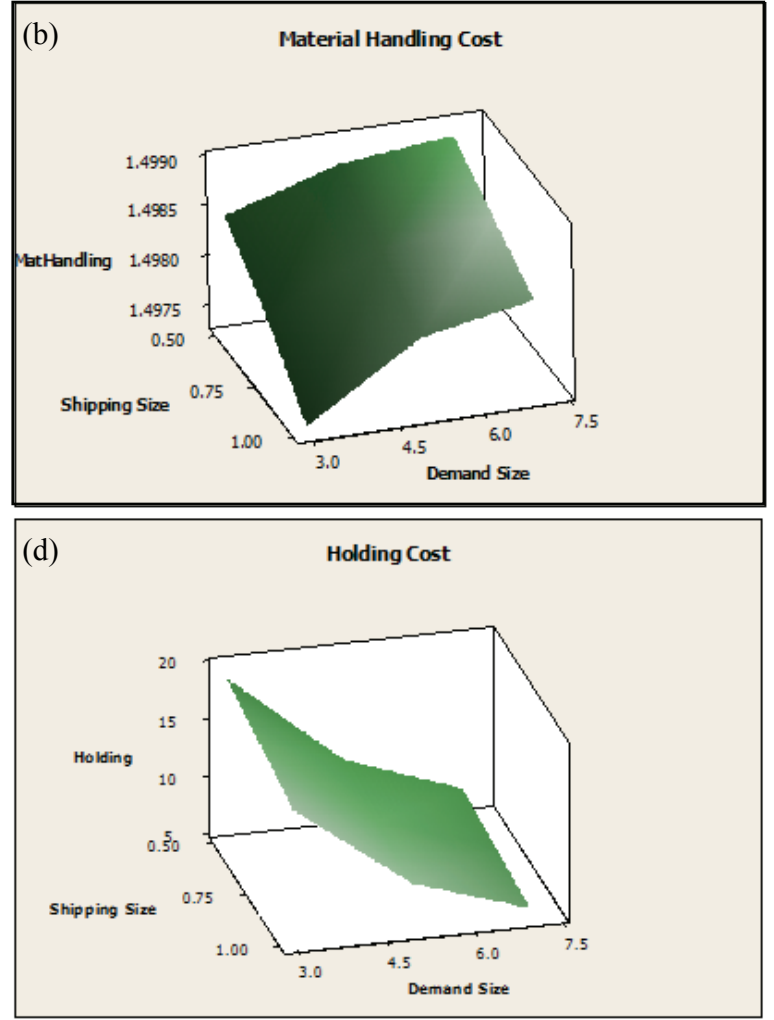

5d). In addition, the ratio of cost decrease is high relative to the demand size. The interaction between the large demand size and the large shipping size shows the lowest unit cost level.

The simulation model was run for one year with a one month warm-up period. The warm-up period is not counted in the results, therefore, the output data is collected for 11 months. The output is measured by the unit cost of each item of trucking, material handling, ordering, holding and facility costs as shown in Table 2. The number of orders is used as a numerator to get the unit costs.

Prior analysis is based on the point estimators of the replication parameters $\mu$, which vary from cost behavior on different sets of observations. This paper 
Table $2 \quad 95 \%$ confidence interval for all scenarios.

\begin{tabular}{|c|c|c|c|c|c|c|c|c|c|}
\hline \multirow{2}{*}{$\begin{array}{l}\text { Demand size } \\
\text { Load factor }\end{array}$} & \multicolumn{3}{|c|}{$3,000,000$} & \multicolumn{3}{|c|}{$5,000,000$} & \multicolumn{3}{|c|}{$7,000,000$} \\
\hline & 0.50 & 0.75 & 1.00 & 0.50 & 0.75 & 0.10 & 0.50 & 0.75 & 1.00 \\
\hline Upper limit & 51.2 & 44.1 & 39.2 & 38.3 & 31.6 & 27.2 & 32.9 & 26.2 & 21.8 \\
\hline Lower limit & 51.0 & 43.9 & 38.9 & 38.3 & 31.5 & 27.0 & 32.7 & 26.1 & 21.8 \\
\hline
\end{tabular}

constructs interval estimates using 95\% confidence intervals to inform the distance of the point estimates from multiple observations. The confidence level was computed by adding the half-width to the average value of the samples $\bar{x}$. The unknown true mean lies within the interval between the lower limit and upper limit. The desirable interval would be narrow with a high confidence level of over $90 \%$ [22].

The scenario with the LTL shipments (load factor: $0.5)$ and 3 million in demand indicates the worst case, while the scenario with TL shipments (load factor: 1.0) and 7 million in demand indicates the best scenario with regard to the unit cost. Little difference is found between the scenarios of TL shipments with 3 million in demand and the LTL shipments with 5 million in demand. In the author's study, high demand generates lower unit costs relative to smaller demand scenarios. The TL shipment scenarios, regardless of demand size, show lower unit costs than the LTL shipment scenarios. Obviously, the LTL shipments do not suit to the high demand sizes by because they result in inefficiency in terms of the unit cost.

\subsubsection{Implications}

It is essential to understand the balancing of inbound and outbound rate and flow speed in a logistic inventory process. The implications explain the behavior of logistics cost. Inbound rate is a replenishment rate and outbound rate is represented by demand size in this study. The demand size is categorized into three echelons. When the replenishment rate is high and demand size is small, holding cost, handling cost and shipping cost are high. TL shows high replenishment rate in this case and LTL with a large fleet is a source of fast replenishment rate. Conversely, when replenishment rate is low and demand size is high, stock out cost is incurred. LTL without increasing fleet size shows a slow replenishment rate with a long queue at a loading facility. When inbound and outbound rate is balanced, the cost is affected by the average rate that the products are moved from origin to destination.

For fast-moving products with a high demand, handling cost and shipping cost is high. One-for-one policy incurs fast rate of flow because of immediate information sharing via the OMS (order management systems). LTL shipments with less than a 1.0 load factor and with increasing capacity would incur a high flow rate. When the flow rate is slow, stock out cost is high because the fast flow rate cripples the balance between inbound and outbound rate.

\section{Conclusions}

This study looks at the trade-offs among inventory cost, shipping cost and stock out cost for a multi echelon inventory management system. The total logistics cost in the system is controlled by replenishment rates and flow rates from the higher echelon (called source nodes) to lower echelon (called sink nodes). High inventory cost results from fast replenishment rates and frequent orders. High shipping cost results from fast flow rates in a process and total traveling time or total traveling distance. Shipping function is an important role which provides balance between inbound and outbound processes. Stock out cost occurred when replenishment rate was slow in the case of high demands and when flow rates were slow between suppliers and customers. Shipping size also has an impact on the level of service and the total cost along with effective order variability. In the three demands scenarios, TL shows better unit profit as well as cost per unit. As the demand size increases, the unit cost difference decreases. Because the simulation 
results are fueled by profit-driven strategies, the TL strategy, which has a fast replenishment rate and a fast outbound rate, is most suitable for high-demand scenarios. The TL strategy increased the customers' service level and reduced the unit cost.

The average total unit cost is calculated for the $95 \%$ and the $99 \%$ confidence intervals. All values are in different ranges. From the results, it is obvious that a full-truck load is the best way to decrease the unit cost. Trucking cost and holding cost are most critical in the cost model. The TL and LTL show significant differences in transportation cost. The truckload system is the least-cost alternative for both small demand and large demand systems. The range of cost and control of the flow rate between locations are issues to be investigated and explained further with regard to the behavior of the system.

The author recommends that distributors use the truckload shipping approach for frequent orders with large-size batch orders, while less than truckload shipments increase the service level and decrease the logistics costs for less-frequent small orders. Maintaining a large inventory improved customer service levels for the scenario with a large demand with less frequent orders.

\section{Acknowledgments}

The author would like to thank Thomas Jirik and the anonymous referee for the useful comments. An earlier version of the paper was presented in the 2010 Winter Simulation Conference.

\section{References}

[1] I.N. Pujawan, The effect of lot sizing rules on order variability, European Journal of Operational Research 159 (2004) 617-635.

[2] J.S. Tancrez, J.C. Lange, P. Semal, A location-inventory model for large three-level supply chains, Transportation Research Part E 48 (2012) 485-502.

[3] Y.C. Tsao, J.C. Lu, A supply chain network design considering transportation cost discounts, Transportation Research Part E 48 (2012) 401-414.

[4] A.J. Ruiz-Torres, J.E. Tyworth, Simulation based approach to study the interaction of scheduling and routing on a logistic network, in: Proceedings of the 1997 Winter Simulation Conference, USA, 1997, pp. 1189-1194.

[5] P. Suwanruji, S.T. Enns, Evaluating the performance of supply chain simulations with tradeoffs between multiple objectives, in: Proceedings of the 2004 Winter Simulation Conference, USA, 2004, pp. 1399-1402.

[6] S. Jain, C.C. Lim, B.P. Gan, Y.H. Low, Criticality of detailed modeling in semiconductor supply chain simulation, in: Proceedings of the 1999 Winter Simulation Conference, USA, 1999, pp. 888-896.

[7] L. Song, X. Li, A. Garcia-Diaz, Multi-echelon supply chain simulation using metamodel, in: Proceedings of the 2008 Winter Simulation Conference, USA, 2008, pp. 2691-2699.

[8] P.C.J. Kleijnen, Supply chain simulation tools and techniques: A survey, International Journal of Simulation and Process Modeling 1 (2005) 82-89.

[9] S. Anily, A. Federgruen, Two-echelon distribution system with vehicle routing cost and central inventories, Operations Research 41 (1993) 37-47.

[10] W.W. Qu, H.J. Bookbinder, P. Iyogun, An integrated inventory-transaction system with modified periodic policy for multiple products, European Journal of Operational Research 115 (1999) 254-269.

[11] V. Jayaraman, Transportation, facility location, and inventory issues in distribution network design, International Journal of Operations and Production Management 18 (1998) 471-494.

[12] S.K. Chaharsooghi, J. Heydari, I.N. Kamalabadi, Simultaneous coordination of order quantity and reorder point in a two-stage supply chain, Computers and Operations Research 38 (2011) 1667-1677.

[13] C. Salvatore, E. Ciancimino, J.M. Framinan, Inventory policies and information sharing in multi-echelon supply chains, Production Planning and Control: The Management of Operations[Online], 10 (2011) 649-659, http://www.informaworld.com/10.1080/09537287.2010.5 12276 (accessed June 6, 2011).

[14] M. Vroblefski, R. Ramesh, S. Zionts, Efficient lot-sizing under a differential transportation cost structure for serially distributed warehouses, European Journal of Operational Research 127 (2000) 574-593.

[15] C.W. Chu, A heuristic algorithm for the truckload and less-than-truckload problem, European Journal of Operational Research 165 (2005) 657-667.

[16] E. Lee, K. Farahmand, Impact of demand variability on supply chain performance, in: Proceedings of the 2008 Industrial Engineering Research Conference, USA, 2008, pp. 1338-1343.

[17] E. Melachrinoudisa, A. Messac, H. Min, Consolidating a warehouse network: A physical programming approach, 
International Journal of Production Economics 97 (2005) $1-7$.

[18] J. Banks, S.J. Carson, L.B. Nelson, M.D. Nicol, Discrete-event System Simulation, Pearson Prentice Hall, Upper Saddle River, NJ, 2005.

[19] G.R. Sargent, Validation and verification of simulation models, in: Proceedings of the 2004 Winter Simulation Conference, USA, 2004, pp. 17-28.

[20] G.R. Sargent, Verification and validation of simulation models, in: Proceedings of the 2009 Winter Simulation Conference, USA, 2009, pp. 162-176.

[21] K. Farahmand, A. Balasubramanian, Solving logistics and transportation problems in a job shop, in: Proceedings of the 2002 Winter Simulation Conference, USA, 2002, pp. 1052-1059.

[22] C. Harrell, K.B. Ghosh, O.R. Bowden, Simulation Using ProModel ${ }^{2}$, McGraw-Hill Education, Singapore, 2003. 